\title{
Solar forcing of the polar atmosphere
}

\author{
Paul Andrew MAYEWSKI, ${ }^{1}$ Kirk A. MAASCH, ${ }^{1}$ Yuping YAN,${ }^{1,2}$ Shichang KANG, ${ }^{1,3}$ \\ Eric A. MEYERSON, ${ }^{1}$ Sharon B. SNEED, ${ }^{1}$ Susan D. KASPARI, ${ }^{1}$ Daniel A. DIXON, ${ }^{1}$ \\ Erich C. OSTERBERG, ${ }^{1}$ Vin I. MORGAN, ${ }^{4}$ Tas VAN OMMEN, ${ }^{4}$ Mark A.J. CURRAN ${ }^{4}$ \\ ${ }^{1}$ Climate Change Institute, and Department of Earth Sciences, University of Maine, 303 Bryand Global Sciences Center, \\ Orono, ME 04469-5790, USA \\ E-mail: paul.mayewski@maine.edu \\ ${ }^{2}$ China Meteorological Administration, 46 Zhongguancun South Avenue, Beijing 100081, China \\ ${ }^{3}$ Institute of Tibetan Plateau Research, Chinese Academy of Sciences, Beijing 100085, China \\ ${ }^{4}$ Department of the Environment and Heritage, Australian Antarctic Division, and Antarctic Climate and Ecosystems CRC, \\ Hobart, Tasmania 7001, Australia
}

\begin{abstract}
We present highly resolved, annually dated, calibrated proxies for atmospheric circulation from several Antarctic ice cores (ITASE (International Trans-Antarctic Scientific Expedition), Siple Dome, Law Dome) that reveal decadal-scale associations with a South Pole ice-core ${ }^{10}$ Be proxy for solar variability over the last 600 years and annual-scale associations with solar variability since AD 1720. We show that increased (decreased) solar irradiance is associated with increased (decreased) zonal wind strength near the edge of the Antarctic polar vortex. The association is particularly strong in the Indian and Pacific Oceans and as such may contribute to understanding climate forcing that controls drought in Australia and other Southern Hemisphere climate events. We also include evidence suggestive of solar forcing of atmospheric circulation near the edge of the Arctic polar vortex based on ice-core records from Mount Logan, Yukon Territory, Canada, and both central and south Greenland as enticement for future investigations. Our identification of solar forcing of the polar atmosphere and its impact on lower latitudes offers a mechanism for better understanding modern climate variability and potentially the initiation of abrupt climate-change events that operate on decadal and faster scales.
\end{abstract}

\section{INTRODUCTION}

Although the sun is the driver of Earth's climate, demonstrating a direct connection between solar variability and climate change has proved difficult. One of the problems is that while solar particle emissions and shortwave radiation change by large amounts in a solar cycle, total irradiance only varies by $\sim 0.1 \%$ (Wilson and Hudson, 1988) and accurate measurements have only been available in the satellite era. Some associations, however, have been observed between historical records of solar activity and climate change (Lean and others, 1995; Hansen and others, 1998) and also between variability in cosmogenic proxies for solar variability (Stuiver and Braziunas, 1989; Beer, 2000) and millennial-scale variability in paleoclimate records from moraine sequences, Greenland ice cores and North Atlantic marine sediments (Denton and Karlén, 1973; O'Brien and others, 1995; Mayewski and others, 1997; Bond and others, 2001). In addition, a major feature of atmospheric circulation, the polar vortex, has been linked to interactions between Northern Hemisphere tropospheric temperature and wind, North Atlantic storm tracks and solar sunspot cycles (Brown and John, 1979; Nastrom and Belmont, 1980; Tinsley, 1988; Van Loon and Labitzke, 1988; Labitzke and Van Loon, 1989; Venne and Dartt, 1990; Burnett, 1993).

In our examination of the potential link between climate and solar variability, we utilize high-resolution, annually dated, glaciochemical series from ice cores at several sites across West Antarctica (ITASE (International Trans-Antarctic Scientific Expedition) 00-1 and 01-2; Siple Dome (Kreutz and others, 1997)) and East Antarctica (Law Dome (Palmer and others, 2001a; Souney and others, 2002)) (Fig. 1) and examples from several older Northern Hemisphere ice cores introduced later in this study.

The Antarctic ice-core series are converted to proxies for atmospheric circulation using calibration techniques and correlations previously described (e.g. Kreutz and others, 2000; Meeker and Mayewski, 2002; Souney and others, 2002) that invoke climate data available from the US National Centers for Environmental Prediction/US National Center for Atmospheric Research (NCEP/NCAR) re-analysis (Kalnay and others, 1996) and other climate indices. Correlations are robust over the full interval of NCEP/NCAR re-analysis data. We focus our study on the period since AD 1400 to avoid proxy calibration complications related to changes in climate boundary conditions that may have occurred prior to the AD 1350-1400 transition from the Medieval Warm Period to the Little Ice Age.

Dust from Australia, Africa and South America and sea salt from the Southern Ocean are the primary sources for $\mathrm{Ca}^{2+}$ in West Antarctic ice cores. Changes in $\mathrm{Ca}^{2+}$ in the Siple Dome and ITASE 00-1 ice cores (Fig. 1) are correlated with changes in the September-November (SON) surface mean zonal wind surrounding Antarctica, most notably the region close to $40-50^{\circ} \mathrm{S}$ in the Indian and Pacific Oceans (Fig. 1). SON timing is consistent with the seasonal maximum in $\mathrm{Ca}^{2+}$ in Antarctic ice cores (Whitlow and others, 1992; Yan and others, 2005). Siple Dome and ITASE 00-1 $\mathrm{Ca}^{2+}$ annually averaged series are positively correlated ( $r=0.38, P<0.01$ and $r=0.44, P<0.01$, respectively; 3 year smoothed series: $r=0.56, P<0.01$ and $r=0.75$, 
a surface zonal wind anomaly

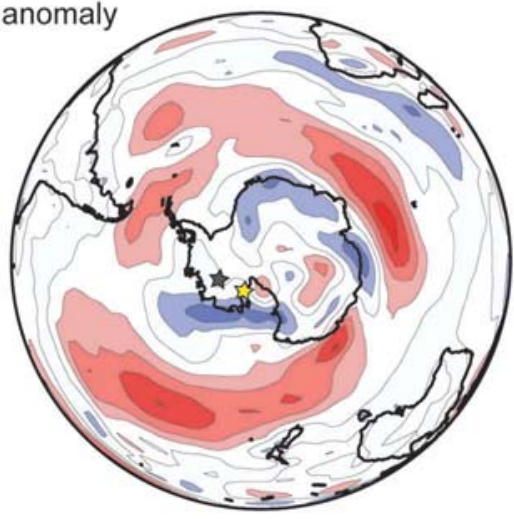

b 850 mbar zonal wind anomaly
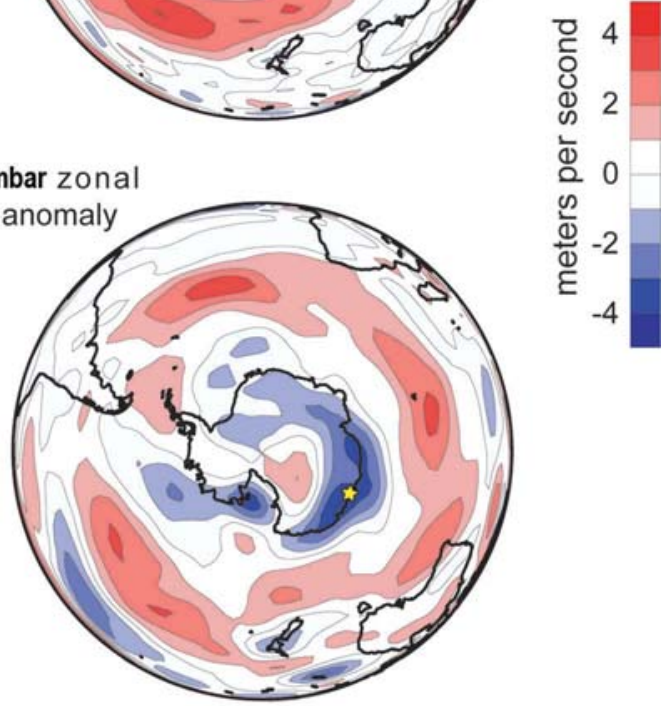

C surface pressure anomaly
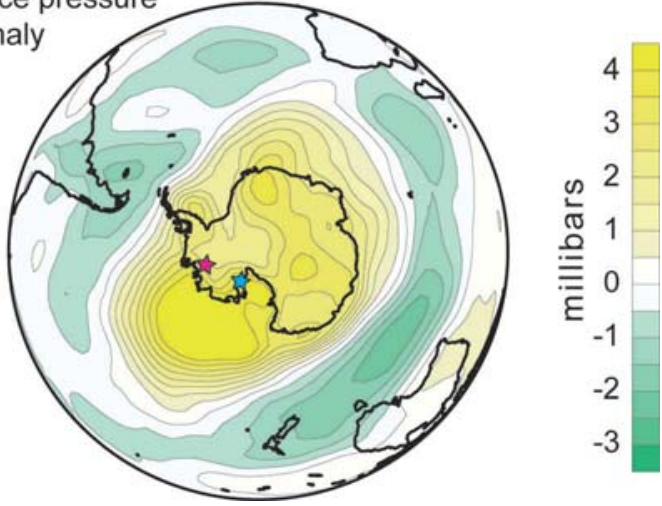

Fig. 1. Ice-core proxies for atmospheric circulation plotted using maps from the NCEP/NCAR re-analysis (US National Oceanic and Atmospheric Administration-Cooperative Institute for Research in Environmental Sciences (NOAA-CIRES) Climate Diagnostics Center, http://www.cdc.noaa.gov/) based on the period AD 1948-2002. (a) Map of SON zonal wind anomalies $\left(\mathrm{m} \mathrm{s}^{-1}\right)$ composited from years where $\mathrm{Ca}^{2+}$ (ITASE 00-1 ice core) exceeds the mean by +1 standard deviation $(+1 \sigma)$ minus years where $\mathrm{Ca}^{2+}$ falls below $-1 \sigma$. Positive (negative) anomalies correspond to increased (decreased) $\mathrm{Ca}^{2+}$. Yellow star (eastern) is location of ITASE 00-1, and yellow star (western) of Siple Dome. (b) Map of JJA 850 mbar zonal wind anomalies composited similarly from $\mathrm{NO}_{3}{ }^{-}$(in the Law Dome ice core) except that the sense is low $(<-1 \sigma)$ years minus high $(>+1 \sigma)$. Thus positive (negative) anomalies correspond to decreased (increased) $\mathrm{NO}_{3}{ }^{-}$. Yellow star is location of Law Dome. (c) Map of SON surface pressure anomalies composited from $\mathrm{Na}^{+}$(in the ITASE 01-2 ice core), in the sense high $(+1 \sigma)$ minus low $(-1 \sigma)$ years. Positive (negative) anomalies correspond to an increase (decrease) in $\mathrm{Na}^{+}$. A major negative anomaly defines the general region of the Amundsen Sea low. Red star is location of ITASE 01-2, and yellow star of Siple Dome.
$P<0.01$, respectively) with the SON surface circumpolar mean zonal wind over the period of NCEP/NCAR re-analysis coverage (AD 1948-2002) (Yan and others, 2005). Anomalies as high as $4 \mathrm{~m} \mathrm{~s}^{-1}$ (Fig. 1) exist in regions where mean (AD 1948-2002) SON winds are $8-12 \mathrm{~m} \mathrm{~s}^{-1}$. From this correlation we demonstrate that stronger (weaker) westerly winds are conducive to more (less) transport of crustal and marine source $\mathrm{Ca}^{2+}$ to both ice-core sites. Correlation between $\mathrm{Ca}^{2+}$ series and higher levels of zonal wind in the atmosphere (500 mbar, not shown) reveals a similar westerly wind influence.

Nitrate ion $\left(\mathrm{NO}_{3}{ }^{-}\right)$input to Antarctica is dominated by transport from long-range sources through the upper troposphere and stratosphere (Legrand and Kirchner, 1990), and, other than sites where significant re-emission to the atmosphere occurs (very low accumulation rate), concentrations range from high to low between inland and coastal Antarctica (Mulvaney and Wolff, 1994). As such, increased levels of $\mathrm{NO}_{3}{ }^{-}$at near-coastal sites such as Law Dome suggest increased transport of inland source air toward the coast. Recent results from an ice core $600 \mathrm{~km}$ east of Law Dome reveal correlations between the JuneAugust (JJA; the period of maximum $\mathrm{NO}_{3}{ }^{-}$input (Whitlow and others, 1992)) surface pressure gradient from East Antarctica to the sub-Antarctic and $\mathrm{NO}_{3}{ }^{-}$in this core $(r=$ $-0.52, \quad P<0.005, A D 1948-90)$ and strong surface wind drainage (Goodwin and others, 2003). We find a similar relationship using changes in Law Dome $\mathrm{NO}_{3}{ }^{-}$and JJA 850 mbar zonal wind. Anomalies in JJA 850 mbar zonal wind up to $4 \mathrm{~m} \mathrm{~s}^{-1}$ over the general region of Law Dome (Fig. 1) are found where the mean (AD 1948-2002) JJA $850 \mathrm{mbar}$ flow is $3-7 \mathrm{~m} \mathrm{~s}^{-1}$. Furthermore, as Law Dome $\mathrm{NO}_{3}{ }^{-}$decreases (increases) there is an increase (decrease) in zonal wind transport over the ocean near $40-50^{\circ} \mathrm{S}$ of up to $3 \mathrm{~m} \mathrm{~s}^{-1}$ where mean (AD 1948-2002) JJA winds are 5$16 \mathrm{~m} \mathrm{~s}^{-1}$ (Fig. 1).

Previous work indicates that higher (lower) $\mathrm{Na}^{+}$concentrations in the Siple Dome ice core are coincident with higher (lower) levels of SON cyclone intensity in one of the major quasi-stationary lows in the circumpolar trough, the Amundsen Sea low (ASL) (Kreutz and others, 2000). SON timing is consistent with the seasonal maximum in $\mathrm{Na}^{+}$in Antarctic ice cores (Whitlow and others, 1992; Kreutz and others, 2000; Steig and others, 2005). The same association is demonstrated for ITASE 01-2 ice core (Fig. 1). Annual values of $\mathrm{Na}^{+}$in the Siple Dome ice core are correlated $(r=-0.32, \quad P<0.001$ (annual series) and $r=-0.51$, $P<0.001$ (3 year smoothed series)) with SON surface pressure changes over much of the South Pacific for the period AD 1900-95 (Kreutz and others, 2000). For the period AD 1948-2002, negative anomalies close to $7 \mathrm{mbar}$ in the region of the ASL are associated with increased levels of Siple Dome $\mathrm{Na}^{+}$(Fig. 1).

In summary, the ice-core records chosen for our study allow tracing of three different transport pathways. Sea-salt $\mathrm{Na}^{+}$(equivalent to total $\mathrm{Na}^{+}$) and some of the $\mathrm{Ca}^{2+}$ associated with sea salt are mainly representative of medium- to low-range circulation, inside the polar vortex. Crustal $\mathrm{Ca}^{2+}$ (most of the $\mathrm{Ca}^{2+}$ identified in the EOF analysis reported below) is representative of zonal atmospheric circulation near the edge of the polar vortex, because its sources are mainly located at $40-50^{\circ} \mathrm{S}$. Nitrate is affected by long-range tropospheric and stratospheric transport with more poorly understood pathways. 


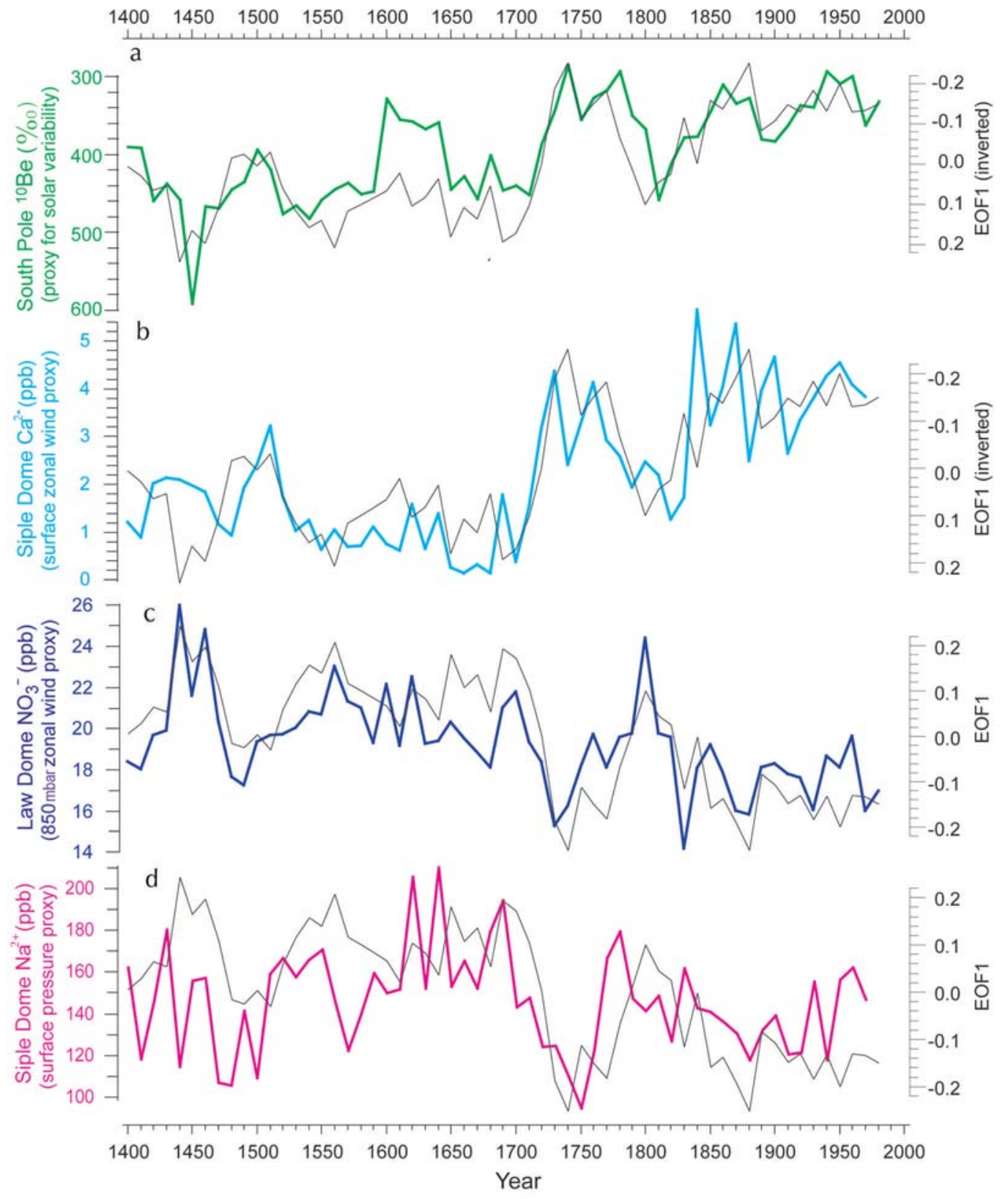

Fig. 2. Jointly associated variance represented by EOF1 (black light line, normalized units) between proxies for solar variability and atmospheric circulation (thick lines) using 10 year resampled data. Proxies are: (a) South Pole ${ }^{10} \mathrm{Be}(\%$ ) proxy for solar variability; (b) Siple Dome $\mathrm{Ca}^{2+}$ (parts per billion (ppb)) proxy for SON surface zonal wind; (c) Law Dome $\mathrm{NO}_{3}{ }^{-}$(ppb) proxy for JJA 850 mbar zonal wind; and (d) Siple Dome $\mathrm{Na}^{+}$(ppb) proxy for SON surface pressure. Proxy for solar variability is plotted as the inverse of the ${ }^{10} \mathrm{Be}$ series $(\mathrm{Bard}$ and others, 2000). EOF1 is oriented in all plots to aid in visually examining the statistical fit.

\section{DECADAL- AND LONGER-SCALE ASSOCIATIONS BETWEEN SOLAR VARIABILITY AND ATMOSPHERIC CIRCULATION}

To investigate the association between solar variability and the ice-core proxies for atmospheric circulation used in this study, we compare the latter to a record of ice-core ${ }^{10} \mathrm{Be}$. The most proximal record for our study comes from a South Pole ice core (Raisbeck and others, 1990). The cosmogenic nuclide data from this study are reported in Bard and others (2000) as changes per mil vs present value and also reported as reconstructed solar irradiance $\left(\mathrm{W} \mathrm{m}^{-2}\right)$ by scaling to various estimates of reductions in solar irradiance during the Maunder Minimum compared to present values (e.g. Zhang and others, 1994; Solanki and Fligge, 1998). Since the South
Pole ${ }^{10}$ Be time series ranges in resolution from 2 to 22 years (mean $7.8 ;<12 \%$ of samples $>10$ year resolution) over the 600 years focused upon in this study, we resample all series to a common 10 year resolution.

Statistical associations between South Pole ${ }^{10} \mathrm{Be}$ and icecore proxies for zonal wind (Siple Dome $\mathrm{Ca}^{2+}$ and Law Dome $\mathrm{NO}_{3}{ }^{-}$) and surface pressure (Siple Dome $\mathrm{Na}^{+}$) are investigated using multidimensional (empirical orthogonal function (EOF)) analysis (Fig. 2) and linear correlations. EOF analysis reveals shared variance between ${ }^{10} \mathrm{Be}$ and the atmospheric proxies. EOF1 contains the greatest shared variance such that $62 \%$ of the ${ }^{10} \mathrm{Be}$ is inversely associated with $60 \%$ of the Siple Dome $\mathrm{Ca}^{2+}$ and directly associated with $61 \%$ of Law Dome $\mathrm{NO}_{3}{ }^{-}$and $30 \%$ of Siple Dome $\mathrm{Na}^{+}$. On EOF2, 58\% of the Siple Dome $\mathrm{Na}^{+}$variance is inversely 

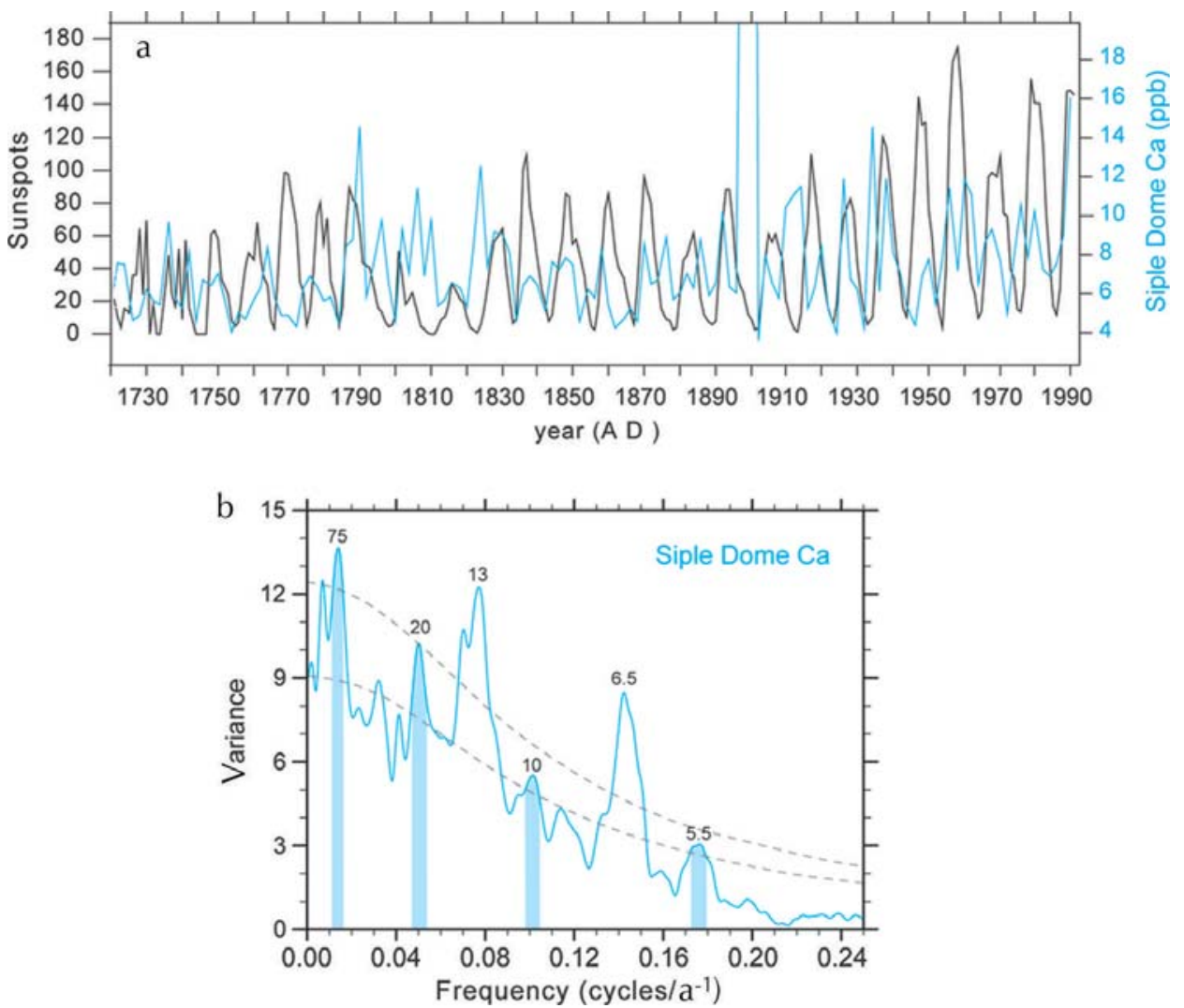

Fig. 3. (a) Annual values of the Siple Dome $\mathrm{Ca}^{2+}$ proxy for surface zonal wind compared to annual values of the solar cycle (sunspot number, ftp.ngdc.noaa.gov) for the period 1720-1990. (b) Multi-taper method (Mann and Lees, 1996): three $2 \sigma$ prolate tapers smoothing of Siple Dome $\mathrm{Ca}^{2+}$. Dashed lines refer to 95\% (lower) and 99\% (upper) significance estimated using a robust red-noise method (Mann and Lees, 1996), and numbers above peaks refer to mean period (years). Periodicities close to previously suggested solar cycles are shaded.

associated with $18 \%$ of the ${ }^{10} \mathrm{Be}$ variance. Remaining EOFs do not reveal significant $(>10 \%)$ variance association between ${ }^{10} \mathrm{Be}$ and the atmospheric proxies. Straight linear correlations between ${ }^{10} \mathrm{Be}$ and Siple Dome $\mathrm{Ca}^{2+}$, Law Dome $\mathrm{NO}_{3}{ }^{-}$and Siple Dome $\mathrm{Na}^{+}$are, respectively, $r=$ $-0.55, r=0.61$ and $r=0.39$ for $P>0.01$ (maximum at 0 lag).

Figure 2 demonstrates the close decadal-scale correspondence between the ${ }^{10} \mathrm{Be}$ ice-core proxy for solar variability and ice-core proxies for polar atmospheric circulation. Shared variance between all of the series is represented by EOF1 in this figure. When solar irradiance increases (decreases), Siple Dome $\mathrm{Ca}^{2+}$ concentrations increase (decrease). From Figure 1 increased $\mathrm{Ca}^{2+}$ is characterized by intensification of zonal winds over, in particular, the Indian and Pacific Oceans. When solar irradiance increases (decreases), Law Dome $\mathrm{NO}_{3}{ }^{-}$ concentrations decrease (increase). From Figure 1 low $\mathrm{NO}_{3}{ }^{-}$is characterized by an increase in zonal wind strength.

Referring to Figure 1, when the $39 \%$ of the variance in Siple Dome $\mathrm{Na}^{+}$associated with ${ }^{10} \mathrm{Be}$ through EOF1 increases (decreases), solar irradiance (inverse of ${ }^{10} \mathrm{Be}$ ) decreases (increases). EOF2 captures $58 \%$ of the joint variance in the inversely associated Siple Dome $\mathrm{Na}^{+}$and ${ }^{10} \mathrm{Be}$ series. Clearly there is a strong but complicated association between solar irradiance and the Siple Dome $\mathrm{Na}^{+}$proxy for the ASL that may be more precisely constrained by investigating the position of the ASL over time through the examination of more ice-core records.

\section{ASSOCIATIONS BETWEEN THE SOLAR CYCLE AND SOUTHERN HEMISPHERE ATMOSPHERIC CIRCULATION}

To further investigate the association between solar irradiance and proxies for zonal wind we compare annual values of these proxies with annual values of the solar cycle for the common period of high-resolution overlap (AD 1720-1990). Although there is a weak identified association between Law Dome $\mathrm{NO}_{3}{ }^{-}$and solar flares (Palmer and others, 2001b), there is no significant correlation between $\mathrm{NO}_{3}{ }^{-}$and sunspot number. However, visual inspection of Siple Dome $\mathrm{Ca}^{2+}$ series compared to the sunspot record reveals similar behaviour and since AD 1825 very nearly in-phase structure (Fig. 3). Differences in phasing between $\mathrm{Ca}^{2+}$ and the sunspot record may be a consequence of dating errors in the older portion of the ice-core record and/or non-linearities in the association between $\mathrm{Ca}^{2+}$ and surface zonal wind produced by changes in boundary conditions, such as seaice extent, not constrained by this study. The largest departure in relative magnitude between $\mathrm{Ca}^{2+}$ and the sunspot record is during the period AD 1896-1901, close to the nominal end of the Little Ice Age. The only other major $\mathrm{Ca}^{2+}$ concentration anomaly of the last 1200 years occurs near the onset of the Little Ice Age (Kreutz and others, 1997). These $\mathrm{Ca}^{2+}$ concentration anomalies (five and ten times, respectively, the mean of the last 1200 years) appear to signal major periods of climate reorganization.

Statistically based associations between solar variability and the Siple Dome $\mathrm{Ca}^{2+}$ proxy for surface zonal wind 

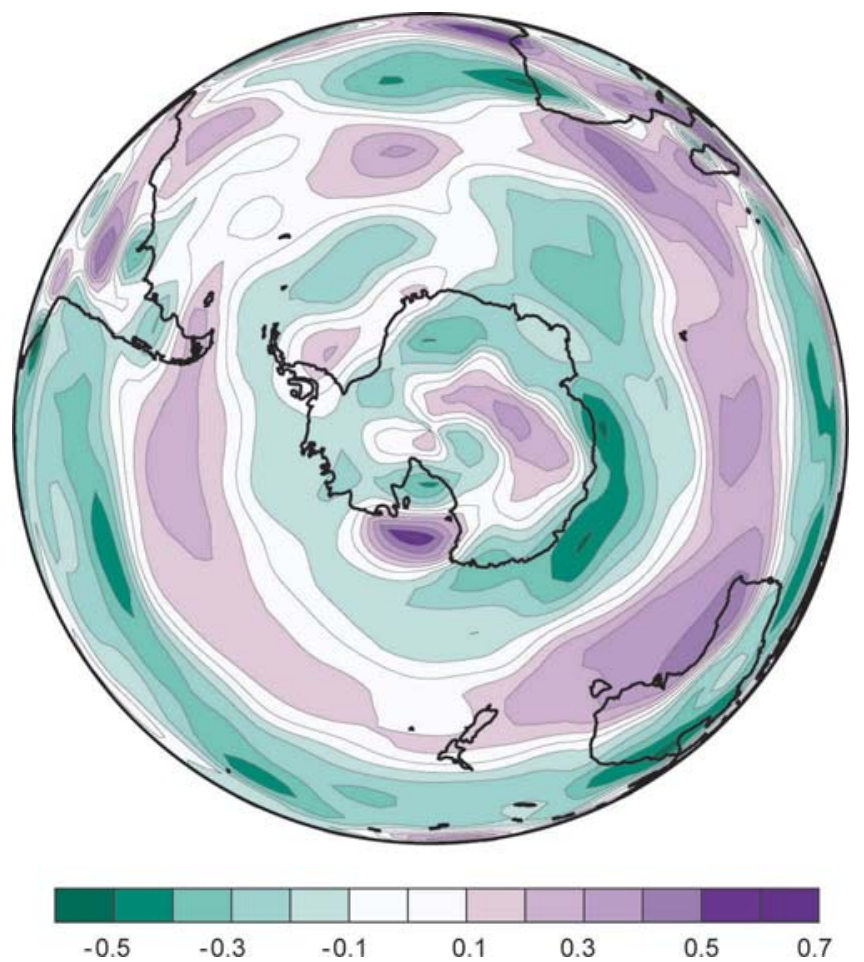

Fig. 4. Association between solar flux and SON surface zonal wind for the period 1975-2002 using an image created on the NCEP/ NCAR re-analysis (NOAA-CIRES Climate Diagnostics Center, http://www.cdc.noaa.gov/). Values of $r>0.345, P=0.990$.

(Fig. 3) reveal significant similarities. Periodicities at 5.5, 10, 20 and 75 years coincide with the 10-11 year Schwabe sunspot cycle, harmonics of the Schwabe cycle ( 5.5 years and the 22 year Hale double sunspot cycle), and are close to the 80-90 year Gleissberg cycle. Highly prominent peaks in the surface zonal wind proxy at 6.5 and 13 years demonstrate that the solar-atmospheric circulation association suggested in this study is only part of a more complex series of controls on Southern Hemisphere atmospheric circulation related perhaps to changes in sea-ice extent and natural oscillations in the ocean-atmosphere system. Alternately dating errors of $\pm 1-2$ years in the older ( $>50$ years) sections of the Siple Dome $\mathrm{Ca}^{2+}$ record may introduce sufficient artefacts in timing to make periodicities of 5.5-6.5 years and 10-13 years not differentiable from the half Schwabe and full Schwabe cycles, respectively.

\section{A MECHANISM FOR SOLAR FORCING OF ATMOSPHERIC CIRCULATION}

While we cannot definitively demonstrate the mechanism by which changes in solar irradiance affect the changes in atmospheric circulation over the Antarctic and Southern Ocean observed in our records, we note that our findings are consistent with other studies, notably, model results and observational data. These suggest that increased solar ultraviolet radiation leads to increased production of stratospheric ozone, resulting in increased (decreased) temperatures in the lower stratosphere (troposphere) (Randel and Cobb, 1994; Chandra and others, 1996; McCormack and Hood, 1996), and consequently an increase in the thermal gradient from high to low latitudes attended by an increase in lower-tropospheric zonal wind speeds over the Northern

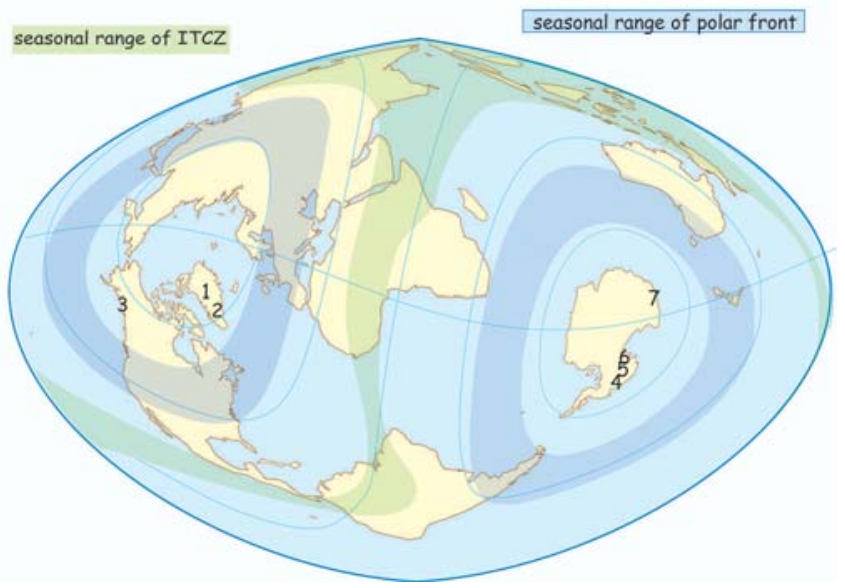

Fig. 5. Eckert-Greifendorff global projection displaying the location of ice-core sites utilized in this study as well as the position of the seasonal range of the northern and southern polar fronts and the Inter-Tropical Convergence Zone (ITCZ) for general perspective. 1. GISP2; 2. 20D; 3. Mount Logan; 4. ITASE 01-2; 5. ITASE 00-1; 6. Siple Dome; and 7. Law Dome.

Hemisphere (Shindell and others, 1999). We note that the association between solar variability and zonal wind speed developed using the NCEP/NCAR re-analysis over the Southern Hemisphere (Fig. 4) is consistent with the solarzonal-wind relationship utilized in this study. It should be noted that recent anthropogenically induced depletion of ozone over Antarctica would subdue the solar-zonal-wind relationship during maxima in the solar cycle. As a consequence, results in Figure 4 may underestimate the natural solar-zonal-wind relationship.

\section{ARCTIC EXAMPLES OF THE ASSOCIATION BETWEEN SOLAR VARIABILITY AND ATMOSPHERIC CIRCULATION}

Northern Hemisphere ice-core records also reveal decadalscale associations with solar variability over the Holocene (O'Brien and others, 1995; Mayewski and others, 1997) and Schwabe cycle periodicities (Mayewski and others, 1993a). To investigate the association between Northern Hemisphere climate and solar variability further, we examine three ice-core records that provide proxies for atmospheric circulation spanning the North Pacific to Eurasia. The Greenland Ice Sheet Project 2 (GISP2) $\mathrm{K}^{+}$record from central Greenland provides a proxy for the behaviour of the Siberian high (Meeker and Mayewski, 2002). The 20D Ca ${ }^{2+}$ record from south Greenland (Mayewski and others, 1993b) is not calibrated with an atmospheric circulation feature but offers evidence of dust transport off adjacent continents through most probably the activity of westerly atmospheric flow. The Mount Logan $\mathrm{Ca}^{2+}$ record from Yukon Territory, Canada, (Mayewski and others, 1993b) reveals statistically significant correlations with the behaviour of the Kara Sea low (E.C. Osterberg and others, unpublished information).

We utilize these records in a preliminary examination only because all are relatively old and the sample resolution and dating for each is generally poorer than the Antarctic records discussed here. Some of these records will be reinvestigated using newly collected ice cores from sites close to the older records, so we present the following 

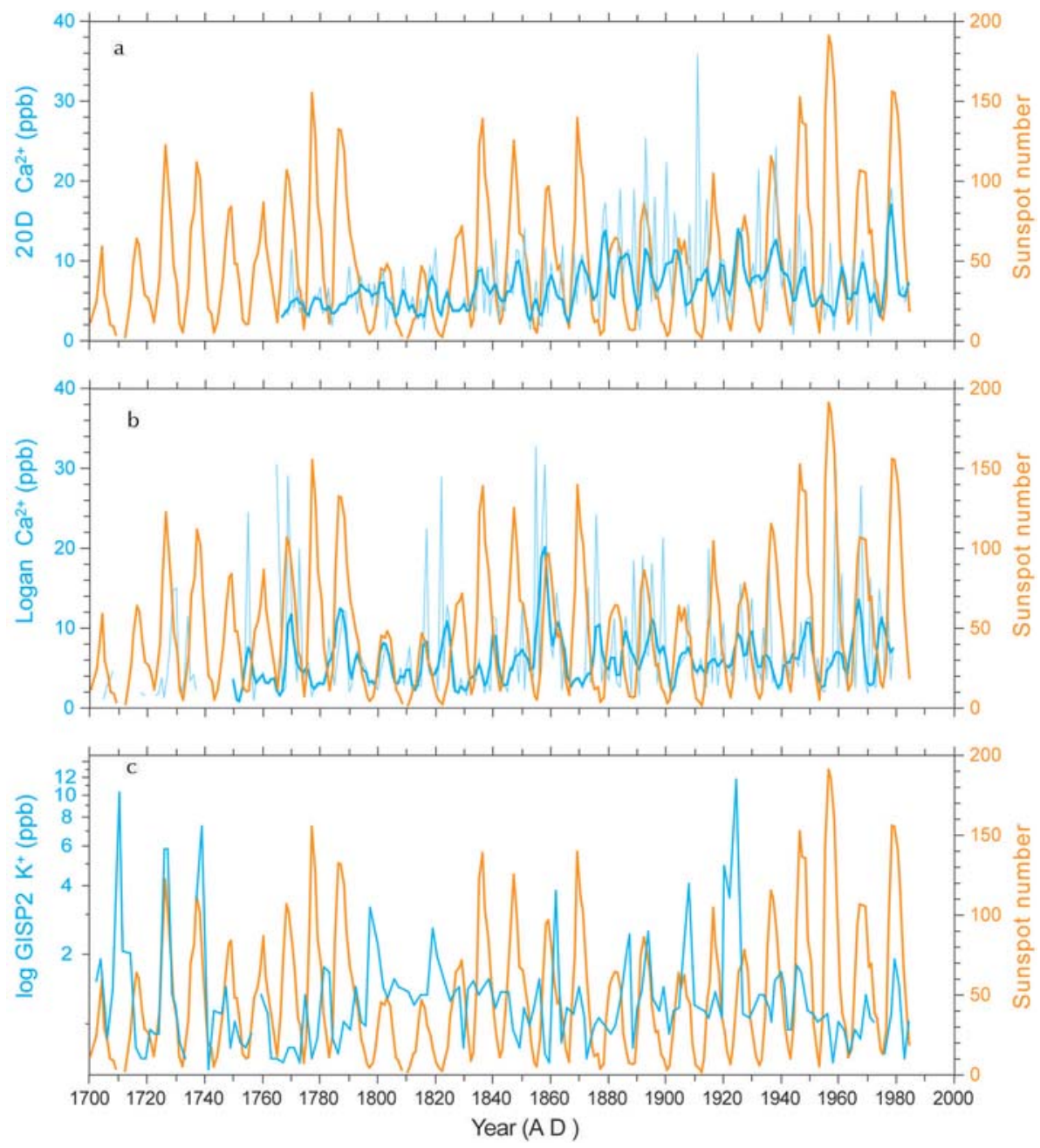

Fig. 6. Sunspot number (ftp.ngdc.noaa.gov) (red) compared to: (a) $20 \mathrm{D} \mathrm{Ca}^{2+}$ annual values (light blue) and robust spline (dark blue); (b) Mount Logan $\mathrm{Ca}^{2+}$ annual values (light blue) and robust spline (dark blue); and (c) GISP2 $\mathrm{K}^{+}$raw data values (dark blue).

primarily to stimulate future investigations. The three icecore records we use in conjunction with the Antarctic data already presented offer a bipolar perspective (Fig. 5) of solar forcing of the polar atmosphere.

In Figure 6 we compare the annually dated portions of these Northern Hemisphere ice-core records with the sunspot record. Since these comparisons are based on older records we will present only a visual examination in this study. Robust splined annual values of $20 \mathrm{D} \mathrm{Ca}{ }^{2+}$ are positively coincident with solar cycles from AD 1983 to 1924, 1896 to 1833 and 1782 to 1764 and more poorly coincident during intervening periods. Positively correlated periods suggest intensified westerly transport during the positive phase of the solar cycle. Robust-splined annual values of Mount Logan $\mathrm{Ca}^{2+}$ are positively coincident with the solar cycle over the periods from AD 1970 to 1892, 1870 to 1840 and 1820 to 1770 and less clearly related during intervening periods. Positively correlated periods reveal intensification of the Kara Sea low coincident with the positive phase of the solar cycle. Raw values of GISP2 $\mathrm{K}^{+}$ coincide positively with solar cycles over the periods AD 1984 to 1936, 1920 to 1890 and 1774 to 1723 and are inverse to the solar cycle throughout much of the intervening portion of the record. Periods with a positive correlation indicate intensification of the Siberian high coincident with the positive phase of the solar cycle.
The positive periods of correlation for these ice-core series and the solar cycle are generally consistent with the timing of periods of greater sunspot activity. In general, the Siberian high, Kara Sea low and westerly flow appear to be intensified (lessened) during the positive (negative) phase of sunspot cycles and most consistently during the positive phase of more active sunspot cycles. Further investigation into the timing and mechanism of the solarclimate association in the Northern Hemisphere must wait for ice cores covering more recent portions of the record.

\section{CONCLUSIONS AND IMPLICATIONS}

In this paper we demonstrate that, on multi-decadal to annual timescales, increases in solar irradiance lead to intensification of zonal winds near the edge of the polar vortex over much of the Southern Ocean and Antarctica and perhaps to intensification of atmospheric circulation throughout portions of the mid-upper latitudes of the Northern Hemisphere. Despite the assertion of a solarclimate association in both hemispheres, comparison between solar-irradiance-induced changes in atmospheric circulation in the Northern and Southern Hemispheres may not be straightforward due to differences in geography between the hemispheres. 
The identification of a solar-climate link and of a possible mechanism for this link will help to elucidate controls on the global climate system and should enhance predictability. However, recent changes in Southern Hemisphere tropospheric circulation, such as anthropogenically driven photochemical ozone depletion in the lower stratosphere over Antarctica (Thompson and Solomon, 2002), and other anthropogenically induced changes in climate will no doubt provide challenges to the natural order imposed by the sunclimate association. Decoding the natural climate system, however, is essential to the prediction of global climate change.

There is significant societal relevance in understanding and eventually predicting the behaviour of climate. For example, Southern Hemisphere circumpolar winds influence atmospheric circulation over the Indian and Pacific Oceans and through this association may change the hydrologic balance over currently drought-ridden portions of Australia.

The solar-irradiance-atmospheric-circulation association suggested here vies for a key role in the control of Holocene, and perhaps older, abrupt climate-change events. The association displays fast onset/decay, broad geographic impact and is consistent with observed and modelled mechanisms for solar-climate forcing. Whether change in solar irradiance can provide sufficient forcing to be the sole trigger for abrupt climate change, or whether it is just sufficient to offset the critical balance of natural oscillations in the climate system, remains to be demonstrated.

\section{ACKNOWLEDGEMENTS}

The authors appreciate the support provided by the 109th Air National Guard, Ice Core Drilling Services, Raytheon Polar Services and many colleagues in the field. The research was funded by the US National Science Foundation (OPP 0096299, 0096305, 0240878) and the Australian Government's Cooperative Research Centres Programme.

\section{REFERENCES}

Bard, E., G. Raisbeck, F. Yiou and J. Jouzel. 2000. Solar irradiance during the last 1200 years based on cosmogenic nuclides. Tellus, 52(3), 985-992.

Beer, J. 2000. Polar ice as an archive for solar cycles and the terrestrial climate. In Wilson, A., ed. The Solar Cycle and Terrestrial Climate: Proceedings of the First Solar and Space Weather Euroconference, Santa Cruz de Tenerife, September 25-30. Noordwijk, European Space Agency, 671-676.

Bond, G. and 9 others. 2001. Persistent solar influence on North Atlantic climate during the Holocene. Science, 294(5549), 2130-2136.

Brown, G.M. and J.I. John. 1979. Solar cycle influences in tropospheric circulation. J. Atmos. Terr. Phys., 41, 43-52.

Burnett, A.W. 1993. Size variations and long-wave circulation within the January Northern Hemisphere circumpolar vortex 1946-89. J. Climate, 6, 1914-1920.

Chandra, S. and 6 others. 1996. Ozone variability in the upper stratosphere during the declining phase of Solar Cycle 22. J. Geophys. Res., 23, 2935-2938.

Denton, G.H. and W. Karlén. 1973. Holocene climatic variations: their pattern and possible causes. Quat. Res., 3(2), 155-205.

Goodwin, I., H. De Angelis, M. Pook and N.W. Young. 2003. Snow accumulation variability in Wilkes Land, East Antarctica and the relationship to atmospheric ridging in the $130^{\circ}-170^{\circ} \mathrm{E}$ region since 1930. J. Geophys. Res., 108(D21), 4673. (10.1029/ 2002JD002995.)

Hansen, J., A. Lacis, R. Ruedy, M. Sato and H. Wilson. 1998. Climate forcings in the industrial era. Proc. Nat. Acad. Sci. USA, 95, 12,753-12,758.

Kalnay, E. and 21 others. 1996. The NCEP/NCAR 40-year reanalysis project. Bull. Am. Meteorol. Soc., 77(3), 437-471.

Kreutz, K.J. and P.A. Mayewski. 1999. Survey of Antarctic surface snow glaciochemistry. Antarct. Sci., 11(1), 105-118.

Kreutz, K.J., P.A. Mayewski, L.D. Meeker, M.S. Twickler, S.I. Whitlow and I.I. Pittalwala. 1997. Bipolar changes in atmospheric circulation during the Little Ice Age. Science, 277(5330), 1294-1296.

Kreutz, K.J., P.A. Mayewski, I.I. Pittalwala, L.D. Meeker, M.S. Twickler and S.I. Whitlow. 2000. Sea level pressure variability in the Amundsen Sea region inferred from a West Antarctic glaciochemical record. J. Geophys. Res., 105(D3), 4047-4059.

Labitzke, K. and H. van Loon. 1989. Associations between the 11year solar cycle, the QBO and the atmosphere. Part III: aspects of association. J. Climate, 2(6), 554-565.

Lean, J., J. Beer and R. Bradley. 1995. Reconstruction of solar irradiance since 1610: implications for climate change. Geophys. Res. Lett., 22(23), 3195-3198.

Legrand, M.R. and S. Kirchner. 1990. Origins and variations of nitrate in south polar precipitation. J. Geophys. Res., 95(D4), 3493-3507.

Legrand, M. and P. Mayewski. 1997. Glaciochemistry of polar ice cores: a review. Rev. Geophys., 35(3), 219-243.

Mann, M.E. and J.M. Lees. 1996. Robust estimation of background noise and signal detection in climatic time series. Climate Change, 33, 409-445.

Mayewski, P.A. and 8 others. 1993a. Greenland ice core 'signal' characteristics: an expanded view of climate change. J. Geophys. Res., 98(D7), 12,839-12,847.

Mayewski, P.A. and 7 others. 1993b. Ice-core sulfate from three Northern Hemisphere sites: source and temperature forcing implications. Atmos. Environ., 27A(17-18), 2915-2919.

Mayewski, P.A. and 6 others. 1997. Major features and forcing of high-latitude Northern Hemisphere atmospheric circulation using a 110,000-year-long glaciochemical series. J. Geophys. Res., 102(C12), 26,345-26,366

McCormack, J.P. and L.L. Hood. 1996. Apparent solar cycle variation in upper stratospheric ozone and temperature: latitude and seasonal variations. J. Geophys. Res., 101(D15), 20,93320,944 .

Meeker, L.D. and P.A. Mayewski. 2002. A 1400-year long record of atmospheric circulation over the North Atlantic and Asia. The Holocene, 12(3), 257-266.

Mulvaney, R. and E.W. Wolff. 1994. Spatial variability of the major chemistry of the Antarctic ice sheet. Ann. Glaciol., 20, 440-447.

Nastrom, G.D. and A.D. Belmont. 1980. Evidence for a solar cycle signal in tropospheric winds. J. Geophys. Res., 85, 443-452.

O'Brien, S.R., P.A. Mayewski, L.D. Meeker, D.A. Meese, M.S. Twickler and S.I. Whitlow. 1995. Complexity of Holocene climate as reconstructed from a Greenland ice core. Science, 270(5244), 1962-1964.

Palmer, A.S., T.D. van Ommen, M.A.J. Curran, V.I. Morgan, J.M. Souney and P.A. Mayewski. 2001a. High precision dating of volcanic events (AD 1301-1995) using ice cores from Law Dome, Antarctica. J. Geophys. Res., 106(D22), 28,089-28,096.

Palmer, A.S., T.D. van Ommen, M.A.J. Curran and V. Morgan. $2001 b$. Ice-core evidence for a small solar-source of atmospheric nitrate. Geophys. Res. Lett., 28(10), 1953-1956.

Raisbeck, G.M., F. Yiou, J. Jouzel and J.R. Petit. $1990 .{ }^{10} \mathrm{Be}$ and ${ }^{2} \mathrm{H}$ in polar ice cores as a probe of the solar variability's influence on climate. Philos. Trans. R. Soc. London A, 330(1615), 463-470.

Randel, W.J. and J.B. Cobb. 1994. Coherent variations of monthly mean total ozone and lower stratospheric temperature. J. Geophys. Res., 99, 5433-5447. 
Shindell, D., D. Rind, N.K. Balachandran, J. Lean and P. Lonergan. 1999. Solar cycle variability, ozone, and climate. Science, 284(5412), 305-308.

Solanki, S.K. and M. Fligge. 1998. Solar irradiance since 1874 revisited. Geophys. Res. Lett., 25, 341-344.

Souney, J.M., P. Mayewski, I. Goodwin, V.I. Morgan and T. van Ommen. 2002. A late Holocene climate record from Law Dome, East Antarctica. J. Geophys. Res., 107(D22), 4608-4617.

Steig, E.J. and 16 others. 2005. High-resolution ice cores from US ITASE (West Antarctica): development and validation of chronologies and determination of precision and accuracy. Ann. Glaciol., 41 (see paper in this volume).

Stuiver, M. and T.F. Braziunas. 1989. Atmospheric ${ }^{14} \mathrm{C}$ and centuryscale oscillations. Nature, 338, 405-408.

Thompson, D.W.J. and S. Solomon. 2002. Interpretation of recent Southern Hemisphere climate change. Science, 296(5569), 895-899.

Tinsley, B.A. 1988. The solar cycle and the QBO influences on the latitude of storm tracks in the North Atlantic. Geophys. Res. Lett., 15(5), 409-412.
Van Loon, H. and K. Labitzke. 1988. Association between the 11year solar cycle, the QBO and the atmosphere. Part II: Surface and $700 \mathrm{mb}$ in the Northern Hemisphere in winter. J. Climate, 1, 905-920.

Venne, D.E. and D.G. Dartt. 1990. An examination of possible solar cycle-QBO effects in the Northern Hemisphere troposphere. J. Climate, 3, 272-281.

Whitlow, S., P.A. Mayewski and J.E. Dibb. 1992. A comparison of major chemical species seasonal concentration and accumulation at the South Pole and Summit, Greenland. Atmos. Environ., 26A(11), 2045-2054.

Wilson, R.C. and H.S. Hudson. 1998. The Sun's luminosity over a complete solar cycle. Nature, 332, 810-812.

Yan, Y., P.A. Mayewski, S. Kang and E. Meyerson. 2005. An ice core proxy for Antarctic circumpolar zonal wind intensity. Ann. Glaciol., 41 (see paper in this volume).

Zhang, Q., W.H. Soon, S.L. Baliunas, G.W. Lockwood, B.A. Skiff and R.R. Radick. 1994. A method of determining possible brightness variations of the sun in past centuries from observations of solar-type stars. J. Astroph., 427, L111-L114. 